\title{
AN EXPECTED COMPLIANCE MODEL BASED ON TOPOLOGY OPTIMIZATION FOR DESIGNING STRUCTURES SUBMITTED TO RANDOM LOADS
}

\section{Miguel CARrasco, Benjamin IVORRA, Rodrigo LECAROS, AND ANGEL MANUEL RAMOS}

\begin{abstract}
In this paper, we focus in developing a stochastic model for topology optimization. The principal objective of such a model is to find robust structures for a given main load having a stochastic behavior. In the first part, we present the expected compliance formulation and some results in topology optimization. Then, in order to illustrate the interest of our approach, we consider a preliminary 3D cantilever benchmark experiment and compare the obtained results with the one given by a single load approach.
\end{abstract}

Mathematics subject classification (2010): 35Q74, 74B05, 74P05, 74S60.

Keywords and phrases: topology optimization, structural optimization, expected compliance model, finite element method.

\section{REFERENCES}

[1] W. AchtZIGer, Topology optimization of discrete structures: an introduction in view of computational and nonsmooth aspects, In Topology optimization in structural mechanics, volume 374 of CISM Courses and Lectures, pages 57-100, Springer, Vienna, 1997.

[2] W. Achtziger, M. Bendsøe, A. Ben-Tal, And J. Zowe, Equivalent displacement based formulations for maximum strength truss topology design, Impact Comput. Sci. Engrg., 4, 4 (1992), 315-345.

[3] F. Alvarez And M. Carrasco, Minimization of the expected compliance as an alternative approach to multiload truss optimization, Struct. Multidiscip. Optim., 29, 6 (2005), 470-476.

[4] M. P. BendsøE And O. Sigmund, Topology optimization. Theory, methods and applications, Springer-Verlag, Berlin, 2003.

[5] A. Ben-TAL AND A. Nemirovski, Robust truss topology design via semidefinite programming, SIAM J. Optim., 7, 4 (1997), 991-1016.

[6] A. Ben-TAL AND M. Zibulevsky, Penalty/barrier multiplier methods for convex programming problems, SIAM J. Optim., 72 (1997), 347-366.

[7] M. CARRASCO, B. IVORRA AND A.M. Ramos, A variance-expected compliance model for structural optimization, Journal of Optimization Theory and Applications, accepted, 2011.

[8] P. Ciarlet, Mathematical Elasticity, Vol. I, Three Dimensional Elasticity, North-Holland, Amsterdam, 1988 .

[9] S. Conti, H. Held, M. PACH, M. RumpF AND R. Schultz, Shape optimization under uncertainty, a stochastic programming perspective, SIAM Journal on Optimization, 19, 4 (2008), 1610-1632.

[10] B. IVorra, B. Mohammadi, AND A.M. Ramos, Optimization strategies in credit portfolio management, Journal Of Global Optimization, 432 (2009), 415-427.

[11] B. IVorra, A. M. Ramos, And B. Mohammadi, Semideterministic global optimization method: Application to a control problem of the Burgers equation, Journal of Optimization Theory and Applications, 135, 3 (2007), 549-561. 
[12] L. D. Landau, E. M. Lifshitz, Theory of Elasticity, Oxford, England: Butterworth Heinemann, 1986.

[13] O. Sigmund, A 99 line topology optimization code written in Matlab, Structural and Multidisciplinary Optimization, 21, 2 (2001), 120-127. 